\title{
THE WILL TO COMMUNICATE
}

\author{
DIANA I. PÉREZ \\ Universidad de Buenos Aires/CONICET \\ dianazerep@gmail.com
}

\begin{abstract}
SUMMARY: In this paper I discuss Rodriguez-Pereyra's claim according to which analytical philosophy should be published exclusively in English. I focus my reply on three issues: (1) the implicit conception of philosophy and of the philosophical practice that underlies his argument, (2) the myth of the "native speaker" and (3) some values that should guide philosophy and which I propose to highlight.
\end{abstract}

KEY WORDS: philosophy, native speaker, analytic philosophy

RESUMEN: En este trabajo discuto la idea de Rodriguez-Pereyra acerca de que la filosofía analítica debería publicarse exclusivamente en inglés. Focalizo mi respuesta en tres temas: (1) la concepción implícita de la filosofía y la práctica filosófica que subyace a su argumento, (2) el mito del "hablante nativo" y (3) ciertos valores que creo que deberían guiar la filosofía y que busco destacar.

PALABRAS CLAVE: filosofía, hablante nativo, filosofía analítica

When I was young I was told that Charles V, Holy Roman Emperor, King of the Romans, Italy and Spain, Archduke of Austria, and Duke of Burgundy (1500-1558) held that there are different languages for different human activities: German for guiding horses, English for ordering dogs, French for diplomacy and Spanish for love. ${ }^{1}$ Leaving aside the historical reliability of this quotation, the idea behind it (and behind Gonzalo Rodriguez-Pereyra's note) is the same: there are appropriate languages for each kind of human activity. Native English-speakers probably feel as uneasy with my starting quotation from Charles V, as I do as a native Spanish-speaking analytic philosopher with Gonzalo's note.

There are many things that can be said about Gonzalo's arguments, but I will concentrate on three issues: (1) the implicit conception of philosophy and of the philosophical practice that underlies them, (2) the myth of the "native speaker" and (3) some values I propose to highlight.

${ }^{1}$ This list is the one I remember from my youth, but it seems that he in fact said: "Hablo español con Dios, italiano con las mujeres, francés con los hombres y alemán con mi caballo." (I am not sure if he said it in Spanish or not). English was of no use for the king or, more likely, he simply did not speak it.... In any case, the idea I want to stress underlying the quotation remains intact no matter what languages and what activities are involved. 


\section{Philosophy and its Practice}

Gonzalo's thesis is the following: "original work of research in analytic philosophy broadly conceived should nowadays be published exclusively in English. Publishing such work in English is very valuable, but publishing it in languages other than English is of little or no value".

The main reason Gonzalo gives in support to this claim is a fact about the number of English potential readers and the number of journals that publish papers in English. But his conclusion includes the word "should". I will leave aside the obvious philosophical difficulties that lie behind the naturalistic fallacy. Instead I will remark that from the very same fact we can draw different norms: for example, in response to the fact that there are less Afro-Americans in universities in the United States many departments adopted the policy of establishing quotas to ensure their presence, and a similar policy has also been applied in the case of women as well as with other minorities. So we might well conclude that the best norm we can draw from the fact that the great majority of papers are published in English is that the journals should establish a quota of foreign languages articles to be included in each number, instead of concluding that it is less valuable to publish in a minority language. Which inference we draw depends upon what other values we decide to adopt.

Leaving aside the question of what norm we can draw from these facts, I would like to focus on the ambiguity of the word "value" in Gonzalo's thesis. In what sense can we affirm that a publication is more valuable than others? Is it valuable for me, the writer, because more people can read my stuff? Or for the whole world, because there is an entirely neutral and disinterested way in which we can measure the value of a paper? Is a philosophy paper a better paper just because it is written in a language or in another one? Is Gödel's theorem less valuable because it was published in German? Or Frege's, Wittgenstein's or Carnap's work? The origin of analytical philosophy is a good counterexample to Gonzalo's thesis. Russell did not decide to write in German in order to communicate with Frege or Wittgenstein, nor did they decide to write in English. The whole point is that they wanted to communicate to each other. Language is just a medium, and, as Davidson argued, there is no need for a common vehicle for communicating if we have the will to communicate. ${ }^{2}$

${ }^{2}$ Davidson says: "Obviously this principle does not demand that speaker and interpreter speak the same language. It is an enormous convenience that many people speak in similar ways, and therefore can be interpreted in more or less 
My second concern is with the (lack of) characterization of what "analytic philosophy broadly conceived" means. Gonzalo is content to give a list of journals which seem to embody the essence (loosely speaking) of analytic philosophy. But his list is incomplete. Why didn't he include journals such as Crítica, Theoria, Análisis Filosófico, Teorema, Principia, Manuscrito or Abstracta, which are journals from Iberoamerican countries, which publish in English (as well as in other languages), and which clearly belong to the analytic tradition? The papers published in those journals (at least those written in English if we follow Gonzalo's line of reasoning) are as "valuable" as any other paper published in the journals that Gonzalo mentions. Or is there something more necessary in order to be a valuable blindreferred paper than to be written in English? If the journals mentioned by Gonzalo decided to admit papers in other languages - as I suggested above - with every other publishing policy remaining the same, would they be less valuable?

In my opinion, the reasons that guide the decisions about what to read (and what to publish) are not just the language in which the paper is written because, as Gonzalo points out, everyone is able to learn a new language if it is necessary to read something we want to read: not only can non-English speakers learn English but also English speakers can learn other languages as well. But it is obvious that there are other reasons that make us prefer to invest our time reading one paper and not another: the quality of the journal, the fame of the author, the accessibility of the journal - some journals are better distributed than others, some figure in more indexes than others, for a variety of reasons-, and so on.

Furthermore, Gonzalo did not include in his list some well known journals such as Ethics, Philosophy and Public Affairs, The Journal of Aesthetics and Art Criticism, Cognition, Mind and Language or Phenomenology and the Cognitive Sciences. Why did he omit them? Are the papers published in them outside "Analytic Philosophy broadly conceived"? And what about books? Traditionally, many philosophical ideas were transmitted by books, not by "papers" in "journals" which are a recent creation, of at most 150 years ago, a brief part of the history of philosophy if we consider philosophy - as we usually do - as a practice born at least 2700 years ago (see Rabossi 2008). Are books less valuable than papers? Is there a

the same way. But in principle communication does not demand that any two people speak the same language. What must be shared is the interpreter's and the speaker's understanding of the speaker's words" (Davidson 1986, p. 98; I'm using the pagination of the 2005 reprint). 
better language for writing analytic philosophy books? In the case of books, is the language the author chooses irrelevant? Gonzalo's note presupposes that there is a privileged way - papers published in journals - to share our philosophical ideas, but this assumption is highly debatable. Books are publications where style and good writing are an essential ingredient, and as this is the case a good command of the medium also becomes relevant. Gonzalo leaves aside literature, assuming that the boundary between literature and philosophy is clear. But this boundary is not as neat as Gonzalo suppose, at least in the case of philosophy books: Plato and Sartre come to my mind as examples. And if the medium becomes important, we should look at what occurs with literature, and it is a fact that such a great writer as Jorge Luis Borges, despite being almost bilingual, did not write any of his major work in any language other than Spanish, and the same goes for Julio Cortázar or Juan José Saer, who spoke French fluently and who lived most of their lives in France too. So the reasons to prefer (as a writer) one language or another are not merely the number of potential readers we can have.

In the end, I think that my main concern is with Gonzalo's view of philosophy and its practice. Although he is not explicit in this final version of the note, he seems to hold that "academic philosophy" is something we can and should separate from other human practices such as science, art, and what he calls the "popularization of philosophy". And also that "academic philosophy" is to be published exclusively in a small set of academic philosophy journals. I am not denying that there is something we can call "academic philosophy" which is an important part of the standard philosophical practices of our day, but philosophical practice has changed during its history in many respects, including the material support of philosophical ideas, because of the evolution of printing, internet, etc. And "academic philosophy", in my view, is just one possible incarnation of philosophy, and not its essence. I prefer to follow Bernard Williams in understanding philosophy as the rich and changing practice of making sense of our human lives. ${ }^{3}$ In this view, philosophy is closer to literature and history than Gonzalo seems to assume and it cannot be understood as an autonomous enterprise isolated from other cultural enterprises such as science or art. And which kind of philosophy works (academic books, papers, dialogues, meditations, essays, po-

\footnotetext{
${ }^{3}$ Williams 2000, p. 198. (I'm using the pagination of the 2003 reprint.)
} 
ems, aphorisms, etc. $)^{4}$ will be regarded as milestones of philosophy in the future is not something that depends upon the intended audience that philosophers had in mind while writing their works.

\section{The Myth of the Native Speaker}

In response to the third objection he analyzes, Gonzalo holds that "to publish in English one must be able to write reasonably well in English". But what does "reasonably well" mean, at least for the editors of many journals? As a non-native English speaker who wants to publish her works in a foreign language I had to undergo the experience of being pressured to "check the paper with a native speaker". As everyone knows, native speakers have a linguistic competence that serves to avoid grammatical mistakes. But grammatical rules and books also do this job, i.e. help us to avoid mistakes (and Word also does). And when someone masters a language at least in a way in which grammatical, lexical and spelling mistakes are out of the question, what else can the "native speaker" do for us as writers of a philosophical paper in order to improve what we already wrote? What we might need (even in our own language) is someone with superior writing skills who teaches us to improve our writing. All human beings are born with the capacity to learn how to speak and understand a natural language. But writing, and even more so, complex writing such as that involved in producing a professional philosophy paper, is not something a human being can do just because their natural language is this or that. There are explicit but mostly implicit norms that govern the art of writing a professional philosophy paper, and part of the training for philosophers-to-be is acquiring the ability to write a paper according to these norms. But these rules are the same across countries and languages, at least inside the analytical tradition. It is plausible to assume that when someone has learned these rules in her natural language, she can write a good philosophical paper in whatever language she masters. So, what is the point of "checking the paper with a native speaker"? As a matter of fact, it seems to be a polite way to say: you do not belong to our community. It is not just a matter of good English skills, but a subtle new way to discriminate against people who do not belong to the community behind the journal.

${ }^{4}$ I am thinking of Kant's Critique of Pure Reason, Russell's "On Denoting", Berkeley's and Plato's dialogues, Descartes' Meditations on First Philosophy, Locke's Essay, Parmenides' Poem, and Heraclitus' and Wittgenstein's aphorisms. 
Philosophical ideas and arguments do not have gender, nor race, nor religion, nor nationality, and they can be expressed in whatever language we want. The ideas and arguments remain the same (as good or as bad, no matter the language chosen). But ideas and arguments are held by particular persons embedded in different contexts and with different histories, races, genders, religions, nationalities and natural languages. All these differences should not be relevant when listening to someone who wants to express her ideas. Once again, if there exists the will to communicate, if there exists the will to hear what other people even living far away and belonging to different cultures want to say, the language in which ideas are expressed is not important, it might depend upon diverse contingent matters. The conclusion could be, as Gonzalo proposes, that everybody should choose English as their way of expressing their ideas, because, in the end, the language chosen does not matter. But it could also be the opposite one: if the language chosen is not important and what matters is what it is said, then if I want to say it in Spanish, Italian or Chinese it makes no difference. And, as I argued in the previous paragraph, the reasons why we choose a language or other in order to express our thoughts are not merely "pragmatic" but quite complex.

\section{The Will to Communicate}

As I said above, in the end the question is what we think philosophy is, and what values we consider to be at the top of the ranking of our philosophical practices. In my opinion some values we should adopt for guiding our activity as philosophers are: freedom to present our ideas in the way we want; tolerance to accept what is different from us; curiosity and lack of prejudice in order to search — across the borders of languages - for the interesting and original ideas presented by our fellows. And none of these values guide me to recommend anyone to write in any particular language. ${ }^{5}$

\section{REFERENCES}

Davidson, D., 1986, “A Nice Derangement of Epitaphs", in R. Grandy and R. Warner (eds.), Philosophical Grounds of Rationality, Oxford

${ }^{5}$ This paper was improved due to helpful conversations about these and others related topics with Alberto Moretti and Eammon McDonagh (my "English native speaker" advisor). 
University Press, Oxford. (Reprinted in Truth, Language and History, Oxford University Press, Oxford, 2005, pp. 89-107.)

Rabossi, E., 2008, En el comienzo Dios creó el canon, Gedisa, Buenos Aires. Williams, B., 2000, "Philosophy as a Humanistic Discipline", Philosophy, vol. 75, no. 4, pp. 477-496. (Reprinted in Philosophy as a Humanistic Discipline, Princeton University Press, Princeton, 2003, pp. 180-199.)

Received: May 16, 2011; accepted: September 28, 2012. 